\title{
Enfermería en Colombia en tiempos de la pandemia por coronavirus.
}

\section{Claudia Marcela Velásquez-Jiménez*}

El 2020 pasará a la historia de la humanidad como el año en que el mundo global, tecnológico, altamente científico, industrializado e interconectado se transformó por el impacto de un virus desconocido que hizo su aparición en Wuhan, China. Esta pandemia invadió el globo terrestre de manera exponencial desbordando cualquier capacidad de planeación, previsión y respuesta, ocasionando la más alta y rápida morbimortalidad hasta entonces conocida en este siglo (1).

Los sistemas de salud, ante la mirada atónita de las sociedades, han afrontado su dificultad de atender y dar respuesta a las necesidades de la población y uno a uno, han mostrado las grandes fracturas y dificultades en las estrategias de atención a la pandemia; ante esta situación ninguno estaba totalmente preparado y el personal sanitario más que héroes, se han convertido en víctimas del sistema, porque no cuentan con las condiciones fundamentales para que su trabajo sea seguro y exitoso (2-4). En ese contexto, el propósito de esta editorial es plantear algunas reflexiones relacionadas con la respuesta del sistema de salud colombiano ante esta situación; también, se presentan las acciones que desde la enfermería se han venido realizando frente ante tan difícil panorama, que aún hoy es incierto.

\section{El COVID-19 y la respuesta de Colombia}

La enfermedad por Coronavirus, (Coronavirus Disease 2019, COVID-19) es una nueva patología causada por la infección por parte del Coronavirus que causa el Síndrome Respiratorio Agudo Severo o Grave 2 (severe respiratory acute syndrome 2, SARS-CoV-2). Este virus apareció en diciembre de 2019 en pacientes de la ciudad Wuhan, provincia de Hubei, China; debido al aumento progresivo de casos en el mundo se convirtió en pandemia $(5,6)$.

En Colombia se hizo presente el 6 de marzo de 2020, cuando se confirmó el primer caso en la ciudad de Bogotá, -una mujer procedente de Italia- y pronto el país se ve enfrentado a tomar decisiones cruciales como el aislamiento social de los adultos mayores de 70 años, de niños, adolescentes y jóvenes. Este evento provocó como consecuencia de mucha presión por parte de las asociaciones de profesionales de salud y de los gobiernos locales, el cierre de fronteras y aeropuertos y a asumir la cuarentena (7).
La ausencia de un tratamiento eficaz y de vacunas y el poder de contagio del virus, puso en alerta al gobierno colombiano, planteándose la necesidad de realizar acciones inmediatas en todos los sectores. En este sentido, las autoridades propusieron una serie de medidas traducidas en diferentes normativas y decretos, para por una parte, frenar el contagio y por otra, preparar el sistema de salud para los peores escenarios, mediante estrategias de ampliación de la capacidad de atención a través de la adecuación de mayor número de unidades de cuidado intensivo (8). Sin embargo, en la medida que ha avanzado la pandemia, se han develado las crisis del sistema de salud del país, que desde hace años viene padeciendo una "enfermedad crónica" estructural cuyos "síntomas" habían sido tratados paliativamente, pero que se han exacerbado con el aumento de casos de contagio y se pueden resumir en tres aspectos:

Condiciones laborales críticas del personal sanitario en general, que, a pesar de ser fundamental, se ve obligado a ofrecer sus servicios a través de contratos por tercerización o por órdenes de servicios, que no dan garantías para un trabajo digno y adecuado.

Condiciones de bioseguridad deficientes, que se evidencian en el limitado acceso a los elementos de protección individual básicos y adecuados según el riesgo; además de la insuficiente infraestructura física y humana disponible en las Instituciones Prestadoras de Servicios (IPS).

Manejo financiero centrado en las Empresas Promotoras de Salud (EPS) que, en un sistema de aseguramiento, se apropian de los recursos, pero que no son eficientes ni efectivas en el pago de los servicios a contratados con las IPS. Este proceder genera a su vez retrasos en los pagos, con deudas millonarias al personal sanitario, propiciando condiciones de pauperización y crisis institucionales en todas las dimensiones, que competen a la gerencia y gestión de servicios.

Lo descrito, se refleja en la dramática situación social y económica generalizada en las redes de salud a lo largo y ancho del país, que reclaman del gobierno estrategias contundentes para la protección biopsicosocial de su talento humano y la disponibilidad de materia prima suficiente para la atención de la pandemia, que en prospectiva no tiene un final cercano $(9,10)$.
Autor de correspondencia

$\bowtie \quad$ Enfermera Magister Psicología Comunitaria. Presidente Consejo Técnico Nacional de Enfermería. Directora del programa de Enfermería de la Universidad de Ciencias Aplicadas y Ambientales U.D.C.A. Correo: mvelasquez@ udca.edu.co Orcid: https://orcid. org/0000-0001 8353-0485 
1794-9831

E-ISSN 2322-7028

Vol. 17 No. 2

May - Ago 2020

Cúcuta, Colombia

\section{La enfermería colombiana ante la pandemia}

En el contexto de la celebración internacional del año de la enfermería, declarada por la OMS a propósito de la conmemoración de los 200 años del natalicio de Florence Nightingale, la enfermería en Colombia se ve enfrentada a la pandemia ocasionada por el coronavirus. En este marco, es necesario destacar, que en medio del esfuerzo nacional de las organizaciones y asociaciones de enfermería, que bajo el liderazgo del Consejo Técnico Nacional de Enfermería, después de muchos años de trabajo, estaban dándole luz a la construcción de la política nacional de talento humano de enfermería y a las estrategias de operatividad de la misma, en el plan decenal 2020 -2030 $(11,12)$. Hay que destacar, que este trabajo se viene realizando a partir de encuentros nacionales con profesionales de enfermería en sus distintos roles asistenciales, académicos, investigativos y directivos. De igual forma, se venía consolidando con el propósito de poner en la agenda del gobierno y de las instituciones de salud, los principales aspectos del ejercicio profesional y las estrategias que pudieran aportar a la solución de las problemáticas laborales y del escaso reconocimiento social, que la profesión de enfermería ha venido experimentando. No obstante, el Covid-19 al desbordar cualquier capacidad de previsión, aparece y pone a prueba los roles y funciones de la enfermería, develando las dificultades y carencias; es por eso, que al mismo tiempo exige de manera irrefutable la responsabilidad y compromiso de asumir el cuidado y atención de las personas enfermas en esta pandemia.

Debe señalarse que el Consejo Técnico Nacional de Enfermería con la Asociación Nacional de Enfermeras de Colombia, la Organización Colegial de Enfermería, la Asociación Colombiana de Escuelas, Facultades de Enfermería y la Asociación Colombiana Estudiantil de Enfermería, en representación de los profesionales y estudiantes de enfermería del país, se han pronunciado de manera enfática ante el gobierno a través de varias comunicaciones, con participación en audiencias públicas ante el Senado de la República, en redes sociales y otros medios de comunicación. Estas actividades se han llevado a cabo para ratificar el compromiso y la disponibilidad del talento humano de enfermería, al asumir su responsabilidad en el cuidado directo a las personas diagnosticadas y a las expuestas a este peligroso virus. Personal sanitario que siempre ha actuado bajo la premisa de la protección ocupacional requerida, para reducir el riesgo de contagio entre nuestro talento humano. De igual manera, se ha instado al gobierno nacional a ofrecer condiciones óptimas de trabajo, a priorizar el cuidado del personal sanitario en general y el de Enfermería en parti- cular, ante el panorama de preocupación general que se ha evidenciado por la vulnerabilidad del sistema de salud, que específicamente en enfermería es donde se ratifican los problemas que por décadas han sido señalados al gobierno. Hay que considerar, por otra parte, que los problemas estructurales de nuestro talento humano de enfermería se resumen en cinco deficiencias: 1) Baja remuneración y contratación por tercerización o por orden de prestación de servicios, tanto de profesionales como auxiliares de enfermería, para quienes en estas condiciones no cuentan con una seguridad social adecuada, que se agudiza por la falta de pago oportuno del salario de varios meses. 2) Escaso reconocimiento laboral y económico, al no tener en cuenta la formación avanzada de los profesionales de enfermería que cuentan con especializaciones, maestrías y doctorados. 3) Insuficiente disponibilidad de elementos de bioseguridad adecuados para cubrir la demanda en todas las instituciones prestadoras de servicios, de manera eficaz y pertinente. 4) Inexistencia de planes institucionales para brindar atención psicológica y apoyo terapéutico al talento humano que aborda la crisis sanitaria. 5) La ratio enfermera-paciente no está equiparada al no existir la suficiente cantidad de personal de enfermería, que pueda atender de forma más individualizada, segura y de calidad (13).

Con relación a la problemática expuesta, es necesario indicar que la situación de contagio actualmente empeora, con un personal sanitario agobiado por la situación laboral incierta y desprovisto de los mecanismos de bioseguridad adecuados, que sufre los embates del Covid-19 y sus graves repercusiones. Situación que se explica, como lo demuestran los datos con corte del 24 de abril del Instituto Nacional de Salud, en donde se señala que en el personal sanitario hay 306 contagiados, de los cuales: 95 son auxiliares de enfermería, 80 médicos, 42 profesionales de enfermería, 11 terapeutas respiratorios, 8 fisioterapeutas y a este momento hay 4 fallecidos (14).En función de los planteamientos anteriores, esperamos que el gobierno nacional logre garantizar de manera eficaz y oportuna la protección del talento humano en salud y abordar de manera exitosa la pandemia. Se trata de que la sociedad en general entienda que las enfermeras y los demás miembros del equipo de salud, no son sus enemigos y se detenga la violencia y el maltrato que se ha desembocado por causa del trabajo con pacientes contagiados. Es por eso que se espera, que una vez finalizada la terrible pandemia que enfrenta el mundo, se produzca como resultado una transformación positiva para todos los sistemas de salud. 
1. Organización Mundial de la Salud. Nuevo coronavirus en China. [Internet] Washington; 2020. [Consultado 10 de abril de 2020]. Disponible en https:/www.who.int/csr/don/12-january-2020-novelcoronavirus-china/es/

2. Muñoz CF. Consulta de opinión: "Héroes o víctimas". [Internet] Bogotá; 2020. [Consultado 15 de abril de 2020]. Disponible en: https://consultorsalud.com/heroes-o-victimas/

3. Organización Mundial de la Salud. La OMS publica directrices para ayudar a los países a mantener los servicios sanitarios esenciales durante la pandemia de COVID-19 [Internet] 2020 [Consultado 10 abril de 2020]. Disponible en: https://www.who.int/es/news-room/detail/30-03-2020-who-releasesguidelines-to-help-countries-maintain-essential-health-services-during-the-covid-19-pandemic

4. Gail M. El colapso de los sistemas sanitarios. Periódico el Global [Internet] 2020. [Consultado 15 de abril 2020]. Disponible en https://elglobal.es/politica/el-colapso-de-los-sistemas-sanitarios-por-elcovid-19-provoca-un-aumento-drastico-de-muertes-prevenibles/

5. Organización Mundial de la Salud. Alocución de apertura del Director General de la OMS en la rueda de prensa sobre la COVID-19 celebrada el 11 de marzo de 2020. [Internet] 2020. [Consultado 15 abril 2020]. Disponible en: https://www.who.int/es/dg/speeches/detail/who-director-general-s-opening-remarks-at-the-media-briefing-on-covid-19---11-march-2020

6. Gómez-Marín JE, González A, Rodríguez-Morales AJ. Pandemia COVID-19: Reflexiones sobre su impacto para la preparación en el control de enfermedades infecciosas en Colombia. Infectio [Internet]. 2020 [Consultado 10 de abril 2020]; 24(3): 141-142. Disponible en: https://www.revistainfectio. org/index.php/infectio/article/view/854/911

7. Ministerio de salud y protección social. República de Colombia. Colombia confirma su primer caso de Covid 19. [Internet]. Bogotá; 2020 [Consultado 10 de abril 2020]. Disponible en: https://www. minsalud.gov.co/Paginas/Colombia-confirma-su-primer-caso-de-COVID-19.aspx

8. República de Colombia. Ministerio de salud y protección social. Resolución 385 de 2020, marzo 12, por la cual se declara la emergencia sanitaria por causa del coronavirus COVID-19 y se adoptan medidas para hacer frente al virus [Internet] Santa Fe de Bogotá: El Ministerio; 2020 [Consultado 15 de abril 2020]. Disponible en: https:/www.minsalud.gov.co/sites/rid/Lists/BibliotecaDigital/RIDE/DE/DIJ/resolucion-385-de-2020.pdf

9. Suárez-Rozo LF, Puerto-García S, Rodríguez-Moreno LM, Ramírez-Moreno. La crisis del sistema de salud colombiano: una aproximación desde la legitimidad y la regulación. Rev Gerenc Polít Salud. 2017; 16(32):34-50. Doi: https://doi.org/10.11144/Javeriana.rgps16-32.cssc

10. Senado de la República de Colombia. Senado en pleno asume el reto de sacar adelante a Colombia de la crisis por Covid-19. [Internet] Bogotá; 2020 [Consultado 15 de abril 2020]. Disponible en: http:// www.senado.gov.co/index.php/prensa/lista-de-noticias/990-senado-en-pleno-asume-el-reto-de-sacaradelante-a-colombia-de-la-crisis-por-covid-19

11. Organización Mundial de la Salud. Año internacional de la enfermería y partería. [Internet] 2020. [Consultado 15 de abril 2020]. Disponible en: https://www.who.int/es/news-room/campaigns/yearof-the-nurse-and-the-midwife-2020

12. Consejo Técnico Nacional de Enfermería. Política nacional de Talento humano en Enfermería -Plan decenal 2020-2030. Documento preliminar, Bogotá. Enero 2020

13. Asociación Colombiana de Facultades y Escuelas de Enfermería. Boletín oficial de las organizaciones y asociaciones de enfermería. [Internet] Disponible en: http://www.acofaen.org.co/index.php/es/ comunicaciones-emergencia-salud-2020

14. Instituto Nacional de salud Colombia. Datos de Personal de salud contagiado por Covid 19 [Internet] Bogotá; 2020. Disponible en: https://www.ins.gov.co/COVID19PERSONALDESALUDCOLOMBIA/Datos-COVID-19-personal-salud-240420.jpg 